OPEN ACCESS

Edited by:

Lacolley Patrick,

Institut National de la Santé et de la

Recherche Médicale (INSERM),

France

Reviewed by:

Mario Kassmann,

Charité Universitätsmedizin Berlin,

Germany

Graziamaria Corbi,

University of Molise, Italy

Valerie Nivet-Antoine,

Université Paris Descartes, France

*Correspondence:

Aline de Freitas Brito

alineebritoo@gmail.com

Specialty section: This article was submitted to

Vascular Physiology

a section of the journal

Frontiers in Physiology

Received: 09 June 2018 Accepted: 11 October 2018 Published: 31 October 2018

Citation:

Brito AdF, Silva AS, de Souza AA,

Ferreira PB, de Souza ILL

Araujo LCdC, Félix GdS,

Sampaio RdS, Silva MdCC, Tavares RL, Pereira RdA, Miranda

Neto M and da Silva BA (2018) Aortic

Response to Strength Training and

Spirulina platensis Dependent on

Nitric Oxide and Antioxidants.

Front. Physiol. 9:1522.

doi: 10.3389/fphys.2018.01522

\section{Aortic Response to Strength Training and Spirulina platensis Dependent on Nitric Oxide and Antioxidants}

\author{
Aline de Freitas Brito ${ }^{1,2 *}$, Alexandre S. Silva ${ }^{2,3}$, Alesandra A. de Souza ${ }^{4}$, Paula B. Ferreira ${ }^{5}$, \\ lara L. L. de Souza ${ }^{5}$, Layanne C. da Cunha Araujo ${ }^{6}$, Gustavo da Silva Félix ${ }^{2}$, \\ Renata de Souza Sampaio ${ }^{5}$, Maria da Conceição C. Silva ${ }^{5}$, Renata L. Tavares ${ }^{7}$, \\ Reabias de Andrade Pereira ${ }^{2}$, Manoel Miranda Neto $^{7}$ and Bagnólia A. da Silva ${ }^{5,8}$ \\ ${ }^{1}$ School of Physical Education, University of Pernambuco, Recife, Brazil, ${ }^{2}$ Post-Graduation Program in Physical Education \\ UPE/UFPB, Recife, Brazil, ${ }^{3}$ Physical Education Department, Health Sciences Center, Federal University of Paraiba, João \\ Pessoa, Brazil, ${ }^{4}$ Federal University of Tocantins, Licentiate in Physical Education, Tocantinópolis, Brazil, ${ }^{5}$ Postgraduate \\ Program in Natural and Synthetic Products Bioactive, Health Sciences Center, Federal University of Paraiba, João Pessoa, \\ Brazil, ${ }^{6}$ Department of Biophysics and Physiology, Institute of Biomedical Sciences, University of São Paulo, São Paulo, \\ Brazil, ${ }^{7}$ Laboratory of Studies of Physical Training Applied to the Performance and the Health, Health Sciences Center, \\ Federal University of Paraiba, João Pessoa, Brazil, ${ }^{8}$ Pharmaceutical Sciences Department, Health Sciences Center, Federal \\ University of Paraiba, João Pessoa, Brazil
}

Studies have shown that supplementation with Spirulina platensis improves vascular reactivity. However, it is unclear whether in association with strength training this effect can be enhanced. Thus, this study aimed to determine the effects of strength training and S. platensis on the reactivity of the aorta from Wistar rat and the possible mechanisms involved. The animals were supplemented with $S$. platensis and divided into sedentary (SG, SG50, SG150, and SG500) and trained groups (TG, TG50, TG150, and TG500). Nitrite, malondialdehyde (MDA) and antioxidant activity were determined by biochemical assays. To evaluate vascular response, cumulative concentration-response curves to phenylephrine (PHE) and acetylcholine (ACh) were constructed. L-NAME was used to assess the participation of nitric oxide (NO). It was observed that the PHE contractile potency was reduced in TG50, TG150, and TG500 groups compared to SG50, SG150, and SG500 groups, respectively. However, the presence of L-NAME increased the contractile response in all groups. Strength training potentiated the increase in relaxing activity induced by $S$. platensis, where the $\mathrm{pCE}_{50}$ values of $A C h$ increased in TG150 and TG500. These responses were accompanied by increased nitrite production, MDA reduction and increased antioxidant activity in the aorta of both TG150 and TG500 groups. Thus, the present study demonstrated that combined with strength training, $S$. platensis potentiates vascular improvement through the participation of $\mathrm{NO}$ and reduction of oxidative stress.

Keywords: Spirulina platensis, exercise, vasorelaxation, vasoconstriction, antioxidant activity 


\section{INTRODUCTION}

Increase in vasoconstrictor response, decrease in vasodilatory capacity and increase in the production of reactive oxygen species (ROS) as a result of decreased antioxidant capacity are associated with cardiovascular risk factors, such as hypertension (Virdis et al., 2013).

Moreover, research has shown that physical training performed regularly promotes improvement of endothelial function by increasing relaxant response and decreasing contractile reactivity (Silva et al., 2011; Blanco-Rivero et al., 2013; Trinity et al., 2013), as well as by having a protective effect against oxidative stress, reducing the production of free radicals and enhancing the activity of antioxidant enzymes (Ferrara et al., 2008; Roque et al., 2013). The performance of aerobic (triathlon), mixed aerobic-anaerobic (soccer), and anaerobic (sprint running) exercises was associated to increase in antioxidant activity in human endothelial cells (Conti et al., 2012).

In relation to strength training, some human research that used indirect methods have identified similar responses in the vascular improvement (Trinity et al., 2013; Beck et al., 2014; Brito et al., 2014; Choi et al., 2016) and antioxidant action (Scheffer et al., 2012). However, studies that explain mechanisms underlying these responses through direct methods, such as vascular reactivity in an animal model are scarce. There are only three studies described by Figard et al. (2006), Harris et al. (2010), and Araujo et al. (2013), however, there was no consensus between protocols. In this view, little attention has been given to the contractile reactivity and possible mechanisms of action.

In addition to the positive action of physical training on the oxidative stress process, bioactivity compounds consumed in the diet or used as supplements provide protection against negative consequences to health (Lau et al., 2007; Scapagnini et al., 2011; Davinelli et al., 2016). In the literature, different studies have consolidated the nature benefit of compounds which are major sources of antioxidants as resveratrol (BarrajonCatalan et al., 2014; Davinelli et al., 2017), Cocoa polyphenols and gamma-3 fatty acids (Manach et al., 2004; Andres-Lacueva et al., 2008; Davinelli et al., 2018). Therefore, we can highlight S. platensis, blue-green algae, due to its diverse biological activities. Indeed, pre-clinical and clinical studies have shown that the intake of $S$. platensis can exert antioxidant action (Wu et al., 2012) and reduction of endothelial dysfunction (Huang et al., 2005). For these reasons, the first hypothesis of this study was that the improvement of antioxidant capacity and endothelial function could result in better response to relaxing agents and decreased vascular reactivity to contractile agents. Besides that, the second hypothesis was that the best antioxidant and endothelial action combined with resistance training could enhance the effects on vascular reactivity in response to exercise.

Nevertheless, the potential synergistic effects of strength training and S. platensis have not yet been described in the literature as vascular protector and antioxidant. Therefore, the aim of this study was to investigate the effects of strength training and S. platensis supplementation on vascular reactivity in the isolated aorta of Wistar rats and to observe if nitric oxide and oxidative stress were involved in this response.

\section{MATERIALS AND METHODS}

\section{Animals}

Male Wistar rats (Rattus norvegicus), weighing between 250 and $300 \mathrm{~g}$, were obtained from the Bioterium Prof. Thomas George of the Research Institute for Drugs and Medicines of UFPB. Before the experiments, the animals were kept under a balanced diet for feed base (Labina ${ }^{\circledR}$ ) with free access to water, ventilation and controlled and constant temperature $\left(21 \pm 1^{\circ} \mathrm{C}\right)$, daily exposed to a $12 \mathrm{~h}$ light-dark cycle, and the light period from 6 a.m. to 18 p.m. All experiments were performed in a period of $8 \mathrm{a} . \mathrm{m}$. to 20 p.m., following the guidelines for the ethical use of animals (Sherwin et al., 2005). All experiments were previously approved by the Ethics Committee on Animal Use from the Center of Biotechnology (CEUA/CBiotec) with certificate number 0511/13.

The animals were divided into sedentary groups and groups subjected to the strength training protocol supplemented with $S$. platensis (50,150, and $500 \mathrm{mg} / \mathrm{kg}$ ) or saline solution orally. Thus, the work had eight groups with 20 rats each: saline sedentary group (SG, control), sedentary group 50 (SG50), sedentary group 150 (SG150), sedentary group 500 (SG500), saline trained group (TG), trained group 50 (TG50), trained group 150 (TG150), and trained group 500 (TG500).

\section{Substances}

Calcium chloride dihydrate $\left(\mathrm{CaCl}_{2} \cdot 2 \mathrm{H}_{2} \mathrm{O}\right)$, potassium chloride $(\mathrm{KCl})$ and sodium bicarbonate $\left(\mathrm{NaHCO}_{3}\right)$ were purchased from Vetec (Rio de Janeiro - RJ, Brazil). Glucose $\left(\mathrm{C}_{6} \mathrm{H}_{12} \mathrm{O}_{6}\right)$, magnesium sulfate heptahydrate, $\left(\mathrm{MgSO}_{4} .7 \mathrm{H}_{2} \mathrm{O}\right)$, hydrochloric acid $(\mathrm{HCl})$ and monobasic potassium phosphate $\left(\mathrm{KH}_{2} \mathrm{PO}_{4}\right)$ were obtained from Nuclear (Porto Alegre - RS, Brazil). Sodium chloride $(\mathrm{NaCl})$ was purchased from Dynamics (Diadema-SP, Brazil). The acetylcholine (ACh) was obtained from Merck (Brazil). Phenylephrine (PHE) was acquired from Pfizer (USA). $N \omega$-nitro-L-arginine methyl ester (L-NAME) was purchased from Sigma-Aldrich (Brazil). The ethylenediaminetetraacetic acid (EDTA) (1:250) was purchased from BioTécnica-Advanced Biotechnology (Brazil). The carbogen mixture $\left(95 \% \mathrm{O}_{2}\right.$ and $5 \%$ $\mathrm{CO}_{2}$ ) was obtained from White Martins (Brazil). All substances were weighed on an analytical balance, model AG 200 GEHAKA (São Paulo-SP, Brazil).

\section{Preparation and Administration of Spirulina platensis}

S. platensis in powder form was obtained from Bio-Engineering Dongtai Top Co. LTD. Laboratory (Nanjing, China) (lot $\mathrm{n}^{\circ}$. 20130320). A sample was analyzed by Pharma Nostra Quality Control Laboratory (Anapolis - GO, Brazil) (lot $\mathrm{n}^{\circ}$. 1308771A) to certify that the extract obtained was from S. platensis. The Dilecta Manipulation Drugstore (João Pessoa) was responsible for the handling and preparation of the dried powder (lot $\mathrm{n}^{\circ}$. 20121025).

The $S$. platensis powder was dissolved in saline solution $(\mathrm{NaCl}$ $0.9 \%$ ) each day for the doses preparation of 50, 150, and 500 $\mathrm{mg} / \mathrm{kg}$ and administered in the animals. The supplementations 
were carried out for a period of 8 weeks for all doses $(50,150$, and $500 \mathrm{mg} / \mathrm{kg}$ /day) (adapted from Juárez-Oropeza et al., 2009). The administration was made orally in the period of $12 \mathrm{p} . \mathrm{m}$. to 14 p.m., using stainless steel needles for gavage (BD-12, Insight, Ribeirão Preto, SP). For groups submitted to strength training, the supplementation was performed $30 \mathrm{~min}$ prior to the exercise session (Stefani et al., 2014).

\section{Strength Training Program}

The animals of the strength training groups were subjected to a specific jumping program in a PVC cylinder, $30 \mathrm{~cm}$ in diameter and $70 \mathrm{~cm}$ high, containing water. The water depth in the tanks was $50 \mathrm{~cm}$, approximately twice the length of the rats, aimed at limiting their attempt to climb the wall to cling to the cylinder edge. Before starting the exercise, the water was heated to about $32^{\circ} \mathrm{C}$, a comfortable temperature for rats exercise (Marqueti et al., 2006).

Strength training was based on the jumping protocol in water, developed by Marqueti et al. (2006). Briefly, the protocol consists of 4 series of 10 to 12 repetitions, with 30 -s intervals between sets, with a progressively increasing load adjusted according to body weight. The load was applied to the chest of the animals using a special vest that allowed the jumps without loosening of the load from the body or preventing their movement. All exercise sessions were always held from 12 p.m. to 14 p.m.

Strength training and adjusting the overload was carried out as follows:

- Week of adaptation-three days of alternate exercise sessions with a load corresponding to 50\% of animal body weight, so that the number of sets and repetitions is adjusted every session and a 30-s rest between sets is added (1st day: 2 sets $\mathrm{x} 5$ jumps; 2nd day: 4 sets $x 5$ jumps; and 3rd day: 4 sets $x 9$ jumps).

- 1 st and 2 nd weeks-4 sets of 10 jumps, with a 30 -s rest between the series and an overload of $50 \%$ of the animal body weight.

- 3rd and 4th weeks-4 sets of 10 jumps, with a 30-s rest between the series and an overload of $60 \%$ of body weight.

- 5th and 6th weeks - the 4 sets of 10 jumps remained, with a $30 \mathrm{~s}$ rest between the series and an overload of $80 \%$ of the animal body weight.

- 7 th and 8th weeks - the 4 sets of 12 jumps remained, with a $30 \mathrm{~s}$ rest between the series and an overload of $80 \%$ of body weight.

During each exercise session, it was determined the series runtime that the animal spent to perform it with the goal of evaluating the exercise effectiveness on muscle strength.

The animals were euthanized by guillotine $48 \mathrm{~h}$ after the last training session and supplementation, to eliminate the acute exercise effect on reactivity.

Among the sedentary groups, only the supplemented with the $500 \mathrm{mg} / \mathrm{kg}$ dose had a significant reduction in body mass as of the 6th week of intervention. In 6th and 7th weeks, their reduction was significant when compared to $S G$ and in 8th week when compared to SG, SG50, and SG150. Among the trained groups, the groups supplemented with S. platensis at doses of $150 \mathrm{mg} / \mathrm{kg}$ and $500 \mathrm{mg} / \mathrm{kg}$ significantly reduced body mass after 6 weeks. However, TG150 showed only significant reduction when compared to SG150 at the end of the 6th, 7th, and 8th weeks.
While for TG500 the reductions were verified when compared with TG, TG50, TG150, and SG500 at the end of the 6th, 7th, and 8 th weeks of intervention.

\section{Muscular Performance}

The strength training followed the progressivity principle of sports training for obtaining improved performance. Thus, this protocol can lead to trauma risk in muscle tissue resulting in local muscle inflammation, increase oxidative stress and muscle wasting (Schoenfeld, 2010).

Initially, to confirm the effectiveness of the exercise protocol used in this study, a muscle performance evaluation was made by the time that the animal expended to perform the exercise series during the intervention period. Furthermore, after 8 weeks training, lactate dehydrogenase (LDH) and creatine kinase (CK) were measured, in order to observe an increase in the activity of these enzymes, fact related to exercise intensity. Without these enzymatic increases, an exaggerated muscular stress and chronic negative effects can be observed.

\section{Determination of Lactate Dehydrogenase Activity and Creatine Kinase Activity}

After euthanasia, $3 \mathrm{~mL}$ of blood was collected by cardiac puncture (Okafor et al., 2011) and, $1 \mathrm{~mL}$ of the collected blood was placed in test tubes without anticoagulant to obtain a serum for determination of CK activity and LDH (Siekmann et al., 2002). $\mathrm{LDH}$ and $\mathrm{CK}$ activities in serum using the commercial kit Labtest (Minas Gerais, Brazil). For CK and LDH assays, $20 \mu \mathrm{L}$ of serum was added to $1 \mathrm{~mL}$ of the reagent according to kit instructions. Absorbance was read in an automatic analyzer, LabMax 240 premium, at $340 \mathrm{~nm}$ for $\mathrm{CK}$ and $\mathrm{LDH}$, at room temperature.

\section{Concentration-Response Curves}

After euthanasia, the thoracic aorta was carefully removed and cleaned to remove the connective and adipose tissues. The aorta was divided into segments of $3-5 \mathrm{~mm}$ in length, individually suspended by means of stainless steel clips in organ baths $(6 \mathrm{~mL})$ (Model OX 04) containing Krebs's solution (mM: NaCl 118.0, $\mathrm{KCl}$ 4.6, $1.1 \mathrm{KH}_{2} \mathrm{PO}_{4}, \mathrm{MgSO}_{4}$ 5.7, $\mathrm{CaCl}_{2} 2.5, \mathrm{NaHCO}_{3}$ 25.0, and glucose 11.0), $\mathrm{pH} 7.4$ adjusted with $1 \mathrm{~N} \mathrm{HCl}$ or $\mathrm{NaOH}$ solution (digital pH meter PG2000 GEHAKA-São Paulo, Brazil) at $37^{\circ} \mathrm{C}$ controlled by a thermostatic pump (BT-60 model, AVS ProjectSão Paulo, Brazil) and gassed with carbogen. The isometric tension was evaluated by isometric force transducers (TIM Model 05), coupled to an amplifier (AECAD04F model), connected to a digital acquisition system with AQCAD version 2.1.6 software to obtain the data, and the ANCAD software was used for analysis.

The preparations were stabilized for a period of $1 \mathrm{~h}$ and maintained under a resting tension of $1 \mathrm{~g}$. During this period, the nutrient solution was renewed every $15 \mathrm{~min}$ to prevent interference of metabolites (Altura and Altura, 1970). After the stabilization period, a contraction was induced by $3 \times 10^{-7} \mathrm{M}$ $\mathrm{PHE}$, and during the tonic component, $10^{-6} \mathrm{M}$ ACh was added to determine endothelium integrity (Furchgott and Zawadki, 1980). The vascular endothelium was considered intact when aortic rings showed relaxation equal to or higher than $50 \%$ of total contraction (100\%), and when relaxation was equal to or less than 
$10 \%$ of total contraction (100\%), they were regarded as lacking functional endothelium.

After endothelium integrity verification, to assess the contractile response of rat aorta with or without functional endothelium, the preparations were washed, and after $30 \mathrm{~min}$, a cumulative concentration-response curve was obtained with PHE $\left(10^{-9}-10^{-3} \mathrm{M}\right)$ in the rat aortic rings of all groups (JuárezOropeza et al., 2009).

After endothelium integrity verification, the relaxing response of rat aorta with functional endothelium was evaluated. The preparations were washed and after $30 \mathrm{~min}$ a new contraction with $3 \times 10^{-7} \mathrm{M}$ PHE was induced, and ACh $\left(10^{-11}-10^{-4}\right.$ $\mathrm{M})$ was added cumulatively to the organ bath during the tonic component of contraction (Heylen et al., 2008).

\section{Nitric Oxide Signaling Pathway Evaluation}

After assessing endothelium integrity, the preparations were washed, and $30 \mathrm{~min}$ later, the tissue was incubated with L-NAME $\left(10^{-4} \mathrm{M}\right)$, a non-selective competitive inhibitor of nitric oxide synthase (NOS) (Juárez-Oropeza et al., 2009) for $30 \mathrm{~min}$, and a cumulative concentration-response curve to PHE $\left(10^{-11}-10^{-3}\right.$ M) was obtained in aortic preparations of all groups. The results were evaluated by comparing the amplitude of the contractile response of rat aorta with the functional endothelium of groups treated with $S$. platensis with that obtained by the average of the maximum amplitudes of control curves in the presence and absence of L-NAME.

\section{Biochemical Measurements}

After euthanasia, $3 \mathrm{~mL}$ of blood was collected by cardiac puncture (Okafor et al., 2011) and, $2 \mathrm{~mL}$ were placed in test tubes with anticoagulant (EDTA) to obtain plasma in order to determine nitrite, malondialdehyde (MDA) and antioxidant activity, using commercial kit. After collection, the samples were centrifuged at $1,207 \mathrm{~g}$ for $15 \mathrm{~min}$ in a CENTRIBIO centrifuge; model $80-2 \mathrm{~B}$ 15ML (Guarulhos- SP, Brazil). The supernatant was transferred to Eppendorf tubes and refrigerated at $-20^{\circ} \mathrm{C}$ until analysis. All analyzes were performed within 7 days after blood collection.

Aortic fragments of $8 \mathrm{~mm}$ in length were obtained for measuring nitrite, MDA, and antioxidant activity, and heart samples for MDA and antioxidant activity measurements. These tissues were quickly removed, cleaned with Krebs's solution to remove the remaining blood, placed in Eppendorf tubes and stored in a freezer at $-80^{\circ} \mathrm{C}$ until analysis.

\section{Evaluation of Nitrite in Plasma and Aorta}

The concentration of nitrite was determined by the Griess method proposed by Green et al. (1981). The Griess reagent was prepared using equal parts of $5 \%$ phosphoric acid, $0.1 \%$ $\mathrm{N}$-1-naphylenediamine (NEED) and 1\% sulfanilamide in 5\% phosphoric acid and distilled water. The assay was performed by mixing $500 \mu \mathrm{L}$ of plasma or aorta homogenate with $500 \mu \mathrm{L}$ of Griess reagent and reading the absorbance at $560 \mathrm{~nm}$ after $10 \mathrm{~min}$. The blank was prepared by mixing $100 \mu \mathrm{L}$ of reagent and $100 \mu \mathrm{L}$ of $10 \%$ potassium phosphate buffer, and the standard curve was constructed using serial dilutions of sodium nitrite $\left(\mathrm{NaNO}_{2}\right)(100,50,25,12.5,6.25,3.12 ; 1.56 \mathrm{mM})$. Absorbance was read in an SP-220 UV-Vis spectrophotometer (Biospectro, Curitiba-PR, Brazil).

\section{Malondialdehyde Determination}

For the analysis of MDA in aorta and heart, tissues were homogenized with $10 \% \mathrm{KCl}$ in proportions of $1: 1$. Plasma and homogenate $(250 \mu \mathrm{L})$ were incubated in a water bath at $37^{\circ} \mathrm{C}$ for $60 \mathrm{~min}$. The samples were precipitated with $400 \mu \mathrm{L}$ of $35 \%$ perchloric acid and centrifuged at $26,295 \mathrm{~g}$ for $10 \mathrm{~min}$ at $4{ }^{\circ} \mathrm{C}$. The supernatant was transferred to new Eppendorf tubes, and $400 \mu \mathrm{L}$ of $0.6 \%$ thiobarbituric acid was added. The tubes were incubated at $95-100^{\circ} \mathrm{C}$ for $30 \mathrm{~min}$. After cooling, the material was read in a spectrophotometer at $532 \mathrm{~nm}$ (Ohkawa et al., 1979).

MDA concentration in each plasma sample or tissue was determined using a standard curve of MDA, obtained on the basis of a standard solution ( $1 \mu \mathrm{L}$ of 1,1,3,3-tetramethoxypropane in $70 \mathrm{~mL}$ of distilled water) diluted in series $(250,500,750$, $1000,1250,1500,1750,2000,2250,2500,2750$, and $3000 \mu \mathrm{L}$ of distilled water). In tissues, the absorbance values obtained were normalized by the given sample volume dry weight.

\section{Antioxidant Activity Evaluation}

The procedure was based on the method described by BrandWilliams et al. (1995) using an aliquot of $1.25 \mathrm{mg}$ DPPH diluted in $100 \mathrm{~mL}$ of ethanol, kept under refrigeration and protected from light (aluminum foil or with amber glass). In centrifugation appropriate tubes, $3.9 \mathrm{~mL}$ of DPPH solution was added along with $100 \mu \mathrm{L}$ of homogenate with $\mathrm{KCl}$ or plasma. The tubes were vortexed and left to stand for $30 \mathrm{~min}$. Then, they were centrifuged at $13,416 \mathrm{~g}$ at $20^{\circ} \mathrm{C}$ for $15 \mathrm{~min}$, and the supernatant absorbance was read in a spectrophotometer at $515 \mathrm{~nm}$. The results were expressed as oxidation inhibition percentage according to the following formula: $\mathrm{AOA}=100-\left([\mathrm{DPPH} \bullet \mathrm{R}]_{\mathrm{T}} /[\mathrm{DPPH} \bullet \mathrm{R}]_{\mathrm{B}}\right.$ $100)$, where $[\mathrm{DPPH} \bullet \mathrm{R}]_{\mathrm{t}}$ and $[\mathrm{DPPH} \bullet \mathrm{R}]_{\mathrm{B}}$ are the concentration of DPPH • remaining after $30 \mathrm{~min}$, measured in the sample $(\mathrm{t})$ and blank (B) prepared with distilled water.

\section{Statistical Analysis}

The results obtained were expressed as the mean and standard error of the mean (SEM). These results were analyzed statistically using Student's $t$-test or two-way analysis of variance (ANOVA) followed by Bonferroni's post-test, and the differences between means were considered significant when $p<0.05$. The $\mathrm{pCE}_{50}$ values were calculated by non-linear regression (Neubig et al., 2003). The maximum effect $\left(E_{\max }\right)$ values were obtained by averaging maximum percentages of contraction or relaxation. All results were analyzed by GraphPad Prism ${ }^{\circledR}$ version 5.01 (GraphPad Software Inc., San Diego, CA, USA).

\section{RESULTS}

\section{Effect of Strength Training and Supplementation With S. platensis on Muscle Performance}

The groups submitted to the strength training program improved their exercise execution time in the 4 th and 8th weeks of training in relation to the first week in TG $(24.0 \pm 2.0$ and $24.0 \pm 3.0$ vs. $30.0 \pm 3.0 \mathrm{~s}$, respectively), TG50 (24.0 \pm 3.0 and $23.0 \pm 2.0 \mathrm{vs}$. 


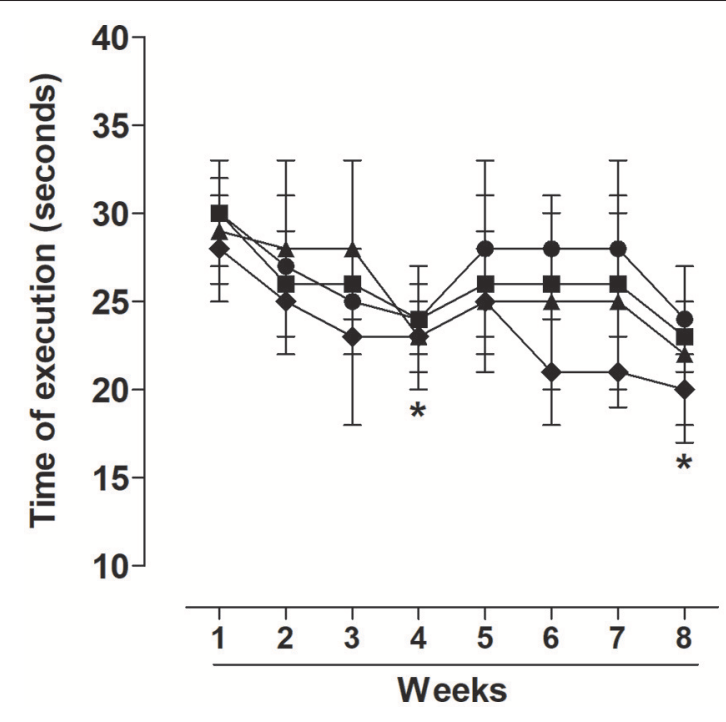

FIGURE 1 | Time of execution of exercise in eight-week training sessions for

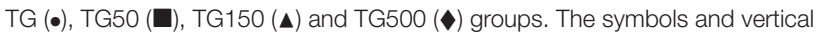
bars represent the mean and SEM, respectively $(n=20)$. Two-way ANOVA followed by Bonferroni's post-test, ${ }^{*} p<0.05$ (TG 1st week vs. TG 4th or 8th week, TG50 1st week vs. TG50 4th or 8th week, TG150 1st week vs. TG150 4th or 8th week, TG500 1st week vs. TG500 4th or 8th week).

$30.0 \pm 2.0 \mathrm{~s}$, respectively), TG150 (23.0 \pm 3.0 and $22.0 \pm 5.0$ vs. $29.0 \pm 3.0 \mathrm{~s}$, respectively), and TG500 (23.0 \pm 2.0 and $20.0 \pm 2.0$ vs. $28.0 \pm 3.0 \mathrm{~s}$, respectively) (Figure 1).

\section{Effect of Strength Training and Supplementation With S. platensis on Muscle Stress and the Cellular Lysis}

Among the trained groups, only the supplemented with $S$. platensis at $500 \mathrm{mg} / \mathrm{kg}$ showed a reduction of LDH when compared to TG $(250.0 \pm 24.0$ vs. $338.0 \pm 60.0 \mathrm{U} / \mathrm{L}$, respectively), TG50 (250.0 \pm 24.0 vs. $347.0 \pm 36.0 \mathrm{U} / \mathrm{L}$, respectively) and TG150 (250.0 \pm 24.0 vs. $335.0 \pm 30.0 \mathrm{U} / \mathrm{L}$, respectively) (Figure 2A). It was also observed that $\mathrm{CK}$ production was decreased in TG500, compared to TG (2842.0 \pm 273.0 vs. 3643.0 $\pm 561.0 \mathrm{U} / \mathrm{L}$, respectively), TG50 (2842.0 \pm 273.0 vs. $3718.0 \pm$ $460.0 \mathrm{U} / \mathrm{L}$, respectively) and TG150 (2842.0 \pm 273.0 vs. $3658.0 \pm$ 460.0 U/L, respectively) (Figure 2B).

The muscle wasting markers $\mathrm{LDH}$ and $\mathrm{CK}$ in the trained groups did not change in relation to the untrained groups, indicating that the training load was well supported by the animals (Figure 2).

\section{Effect of Strength Training and Supplementation With S. platensis on the Contractile Response Induced by PHE in the Presence of Functional Endothelium}

Among the sedentary groups supplemented with S. platensis, only the dose of $500 \mathrm{mg} / \mathrm{kg}$ shifted the cumulative concentrationresponse curve of $\mathrm{PHE}$ to right $\left(\mathrm{pCE}_{50}=5.6 \pm 0.04\right)$ compared to SG, SG50 and SG150 (pCE $\mathrm{p}_{50}=6.1 \pm 0.06,6.2 \pm 0.02$, and 6.2 \pm 0.04 , respectively). Among the animals subjected to strength training and supplementation with S. platensis, doses of 150 and $500 \mathrm{mg} / \mathrm{kg}$ shifted the concentration-response curve to the right compared to TG and TG50 ( $\mathrm{pCE}_{50}=5.3 \pm 0.05$ and $5.0 \pm 0.06$ vs. $5.6 \pm 0.07$, and $5.5 \pm 0.05$, respectively) (Figure 3).

It was observed that the contractile potency of PHE was reduced in $\mathrm{TG}\left(\mathrm{pCE}_{50}=5.6 \pm 0.07\right)$ compared to $\mathrm{SG}$ $\left(\mathrm{pCE}_{50}=6.1 \pm 0.06\right)$ (Figure 3A). This reduction was also observed for TG50 vs. SG50 ( $\mathrm{pCE}_{50}=5.5 \pm 0.05$ vs. $6.2 \pm 0.02$, respectively, Figure 3B), TG150 vs. SG150 ( $\mathrm{pCE}_{50}=5.3 \pm 0.05$ vs. $6.2 \pm 0.04$, respectively, Figure 3C) and TG500 vs. SG500 $\left(\mathrm{pCE}_{50}=5.0 \pm 0.06\right.$ vs. $5.6 \pm 0.04$, respectively, Figure 3D).

The decrease in the contractile potency in SG150 was similar to that in $\mathrm{TG}$ ( $\mathrm{pCE}_{50}=6.2 \pm 0.04$ vs. $5.6 \pm 0.07$, respectively). In addition, the contractile potency induced by $\mathrm{PHE}$ was reduced in TG150 compared to TG and SG150 ( $\mathrm{pCE}_{50}=5.3$ \pm 0.05 vs. $6.2 \pm 0.04$, and $5.6 \pm 0.07$, respectively). In SG500, reduction in $\mathrm{PHE}$ contractile potency was similar to those in $\mathrm{TG}\left(\mathrm{pCE}_{50}=5.6 \pm 0.07\right.$ vs. $5.6 \pm 0.04$, respectively). However, in TG500, the reduction was greater than in TG and SG $\left(\mathrm{pCE}_{50}=5.0 \pm 0.06\right.$ vs. $5.6 \pm 0.07$ vs. $5.6 \pm 0.04$, respectively) (Figure 3).

\section{Effect of Strength Training and Supplementation With S. platensis on Contractile Response Induced by PHE in Absence of Functional Endothelium}

The contractile response induced by PHE in rat aorta without functional endothelium was unchanged with strength training alone when compared to sedentary animals $\left(\mathrm{pCE}_{50}=6.9 \pm\right.$ 0.01 vs. $7.0 \pm 0.01$, respectively) (Figure 4A). Additionally, there was also no change in the trained groups supplemented with $S$. platensis at doses of 50,150 , or $500 \mathrm{mg} / \mathrm{kg}$ when compared to sedentary groups supplemented with $50\left(\mathrm{pCE}_{50}=7.0 \pm 0.01 \mathrm{vs}\right.$. $6.92 \pm 0.01$, respectively, Figure 4B), $150\left(\mathrm{pCE}_{50}=6.9 \pm 0.09\right.$ vs. $7.1 \pm 0.03$, respectively, Figure $4 \mathrm{C})$ and $500 \mathrm{mg} / \mathrm{kg}\left(\mathrm{pCE}_{50}=6.9\right.$ \pm 0.04 vs. $7.0 \pm 0.04$, respectively, Figure 4D). Similarly, the contractile efficacy of PHE was not altered by either strength training or supplementation with $S$. platensis in the absence of functional endothelium.

\section{Effect of Strength Training and Supplementation With S. platensis on Relaxation Induced by ACh}

The ACh relaxing potency was increased when the sedentary animals received supplementation with $S$. platensis at 150 $\left(\mathrm{pCE}_{50}=7.0 \pm 0.08\right)$ and $500 \mathrm{mg} / \mathrm{kg}\left(\mathrm{pCE}_{50}=7.3 \pm 0.02\right)$ when compared to SG and SG50 ( $\mathrm{pCE}_{50}=6.4 \pm 0.06$ and $6.6 \pm$ 0.10 , respectively), no change was observed in $\mathrm{E}_{\max }$. Among the rats subjected to strength training, doses of 150 and $500 \mathrm{mg} / \mathrm{kg}$ increased the $\mathrm{ACh}$ relaxing potency $\left(\mathrm{pCE}_{50}=7.6 \pm 0.08\right.$ and 8.0 \pm 0.04 , respectively) compared to $\mathrm{TG}\left(\mathrm{pCE}_{50}=7.3 \pm 0.02\right)$ and TG50 ( $\left.\mathrm{pCE}_{50}=7.2 \pm 0.07\right)$ (Figure 5).

When comparing the trained and sedentary groups, it was shown that the $\mathrm{pCE}_{50}$ values of $\mathrm{ACh}$ were higher in rats of 

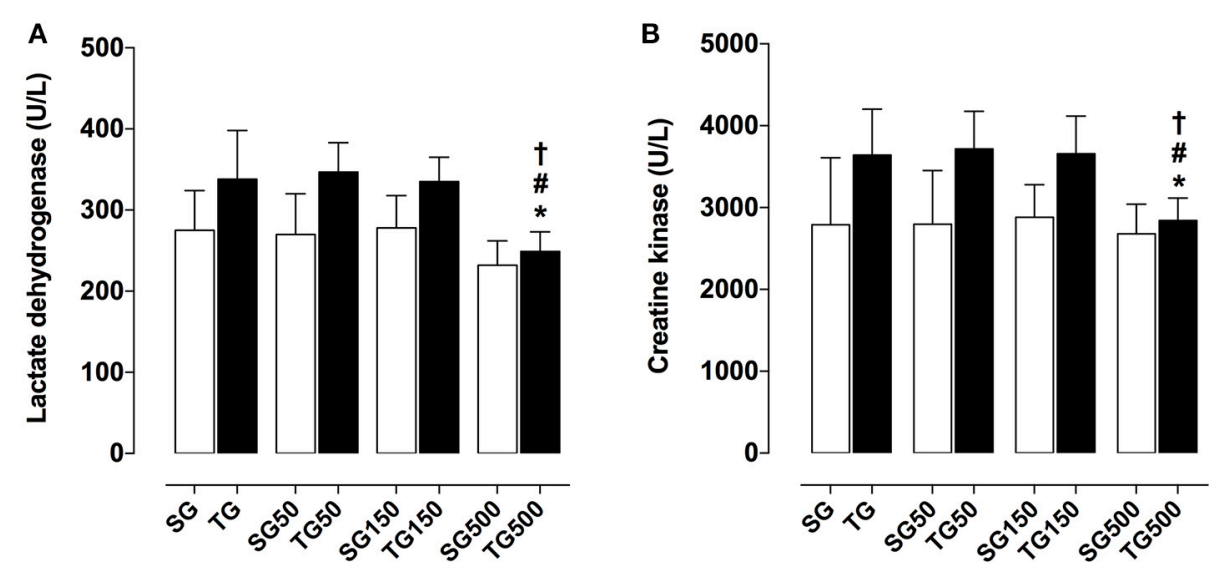

FIGURE 2 | Concentration of lactate dehydrogenase (A) and creatine kinase (B) from SG, TG, SG50, TG50, SG150, TG150, SG500, and TG500 groups. The columns and vertical bars represent the mean and SEM, respectively $(n=8)$. Two-way ANOVA followed by Bonferroni's post-test, ${ }^{\star} p<0.05$ (TG vs. SG500), $\# p<$ 0.05 (TG50 vs. TG500), ${ }^{\dagger} p<0.05$ (TG150 vs. TG500).
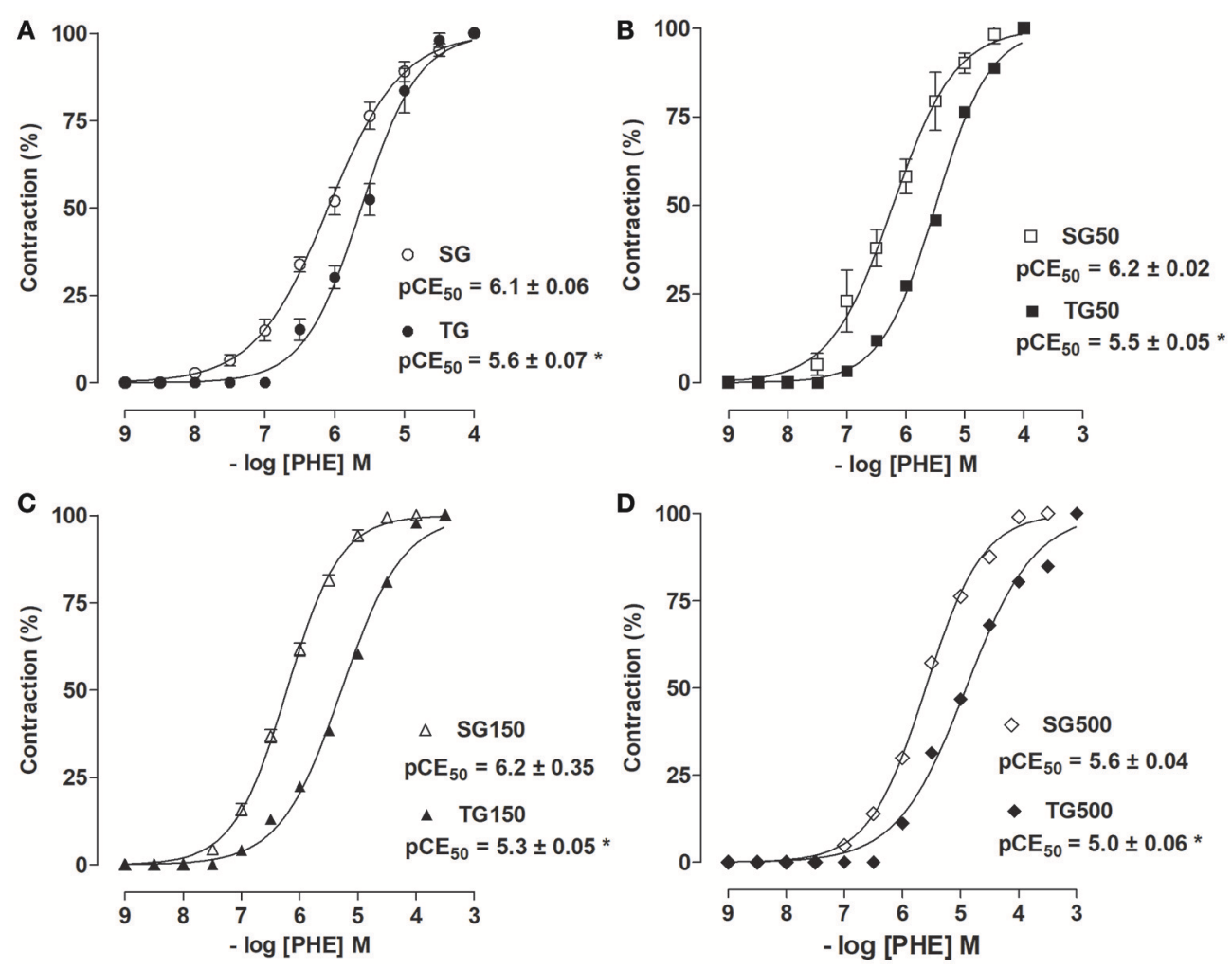

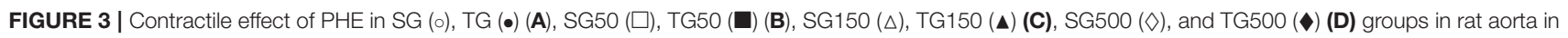
the presence of endothelium. The symbols and vertical bars represent the mean and SEM, respectively $(n=5)$. Student's $t$-test, ${ }^{*} p<0.05$ (SG vs. TG, SG50 vs. TG50, SG150 vs. TG150, SG500 vs. TG500).

TG $\left(\mathrm{pCE}_{50}=7.3 \pm 0.02\right)$ than among $\mathrm{SG}\left(\mathrm{pCE}_{50}=6.4 \pm\right.$ 0.06 ) (Figure 5A). Strength training potentiated the increase in relaxing activity induced by supplementation with $S$. platensis with all doses tested. The $\mathrm{pCE}_{50}$ values of $\mathrm{ACh}$ increased from $6.6 \pm 0.10$ (SG50) to $7.2 \pm 0.07$ (TG50) (Figure 5B), $7.0 \pm$
0.08 (SG150) to $7.6 \pm 0.08$ (TG150) (Figure 5C) and $7.3 \pm 0.02$ (SG500) to $8.0 \pm 0.04$ (TG500) (Figure 5D).

Furthermore, supplementation with $S$. platensis at a dose of $150 \mathrm{mg} / \mathrm{kg}$ in the sedentary group did not cause greater relaxing response compared to $\mathrm{TG}\left(\mathrm{pCE}_{50}=7.0 \pm 0.08\right.$ vs. $7.3 \pm 0.02$, 

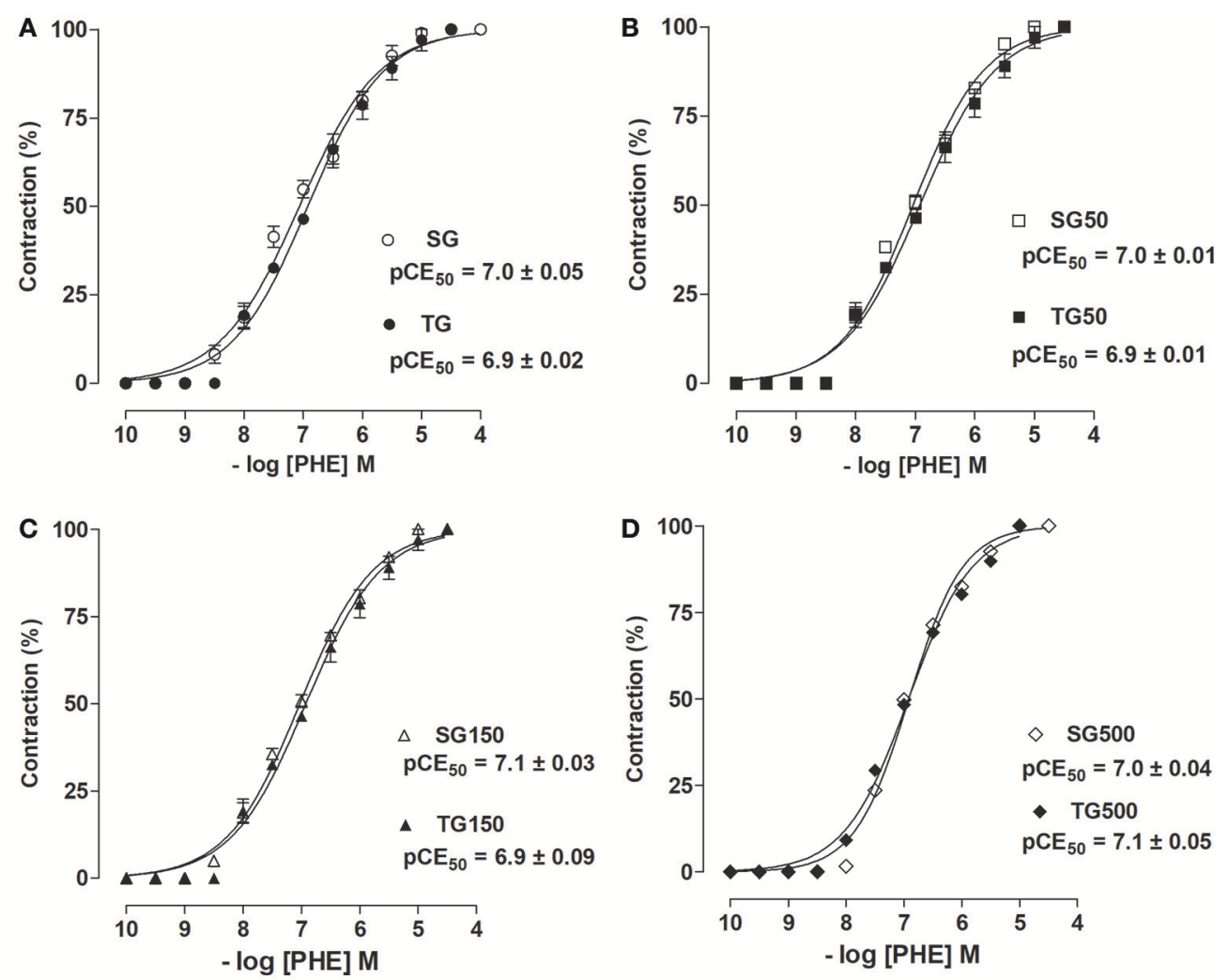

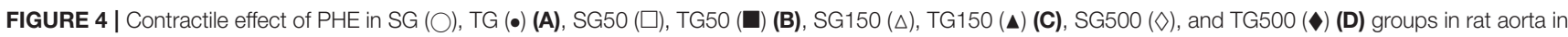
the absence of endothelium. The symbols and vertical bars represent the mean and SEM, respectively $(n=5)$.

respectively). However, in TG150 there was an increase in ACh relaxation potency compared to TG and SG150 $\left(\mathrm{pD}_{2}=7.6 \pm\right.$ 0.08 vs. $7.3 \pm 0.02$ and $7.0 \pm 0.08$, respectively). Moreover, in SG500, there was an increase in relaxation potency similar to that in $\mathrm{TG}$ ( $\mathrm{pCE}_{50}=7.3 \pm 0.02$ vs. $7.3 \pm 0.02$, respectively). However, in TG500, the increase in relaxation potency was higher than TG and SG500 $\left(\mathrm{pCE}_{50}=8.0 \pm 0.07\right.$ vs. $7.3 \pm 0.02$ and $7.3 \pm 0.02$, respectively). Strength training did not change the maximum relaxing effect induced by ACh (Figure 5).

\section{Effect of Strength Training and Supplementation With S. platensis on the Cumulative Contractions Induced by PHE in the Absence and Presence of L-NAME}

The cumulative concentration-response curve to PHE in the presence of L-NAME was shifted to the left in the sedentary group and/or sedentary groups supplemented with 50,150, and $500 \mathrm{mg} / \mathrm{kg} \mathrm{S}$. platensis when compared to SG in the absence of L-NAME $\left(\mathrm{pCE}_{50}=7.1 \pm 0.08,7.1 \pm 0.03,7.6 \pm 0.07,8.2 \pm\right.$ 0.03 , and $6.1 \pm 0.06$, respectively). Similar results were observed in rats subjected to strength training and/or supplementation with $S$. platensis, where there was an increase in contractile reactivity induced by PHE when compared to TG, TG50, TG150, and TG500 groups, in the presence of L-NAME, and TG in the absence of L-NAME $\left(\mathrm{pCE}_{50}=7.5 \pm 0.02,7.5 \pm 0.04,7.9 \pm 0.08\right.$,
$8.6 \pm 0.07$, and $5.6 \pm 0.07$, respectively) in aorta with functional endothelium. Similarly, sedentary animals treated with 150 and $500 \mathrm{mg} / \mathrm{kg}$ of $S$. platensis increased the contractile reactivity of aorta in the presence of L-NAME compared to TG50 and TG in the presence of this inhibitor (Figure 6).

When compared the sedentary groups with strength training groups, it was noted that the contractile potency was higher in $\mathrm{TG}+\mathrm{L}-\mathrm{NAME}$ compared to SG + L-NAME $\left(\mathrm{pCE}_{50}=7.5 \pm\right.$ 0.02 vs. $71 \pm 0.08$, respectively) (Figure 6A). Similar results were observed for supplemented rats, both sedentary and trained. The $\mathrm{pCE}_{50}$ values of PHE increased from $7.5 \pm 0.04$ to $7.1 \pm$ 0.03 (TG50 + L-NAME and SG50 + L-NAME, respectively) (Figure 6B), $7.9 \pm 0.07$ to $7.6 \pm 0.07$ (TG150 + L-NAME and SG150 + L-NAME, respectively) (Figure 6C) and $8.6 \pm 0.07$ to $8.2 \pm 0.03$ (TG500 + L-NAME and SG500 + L-NAME, respectively) (Figure 6D).

\section{Effect of Strength Training and Supplementation With S. platensis on Nitrite Production in Plasma and Aortic Rings}

Plasma nitrite concentration in all groups subjected to strength training was higher than in sedentary groups. The nitrite values in rats subjected only to strength training and sedentary rats were $70.0 \pm 9.0$ and $54.0 \pm 11.0 \mu \mathrm{M}$, respectively. 

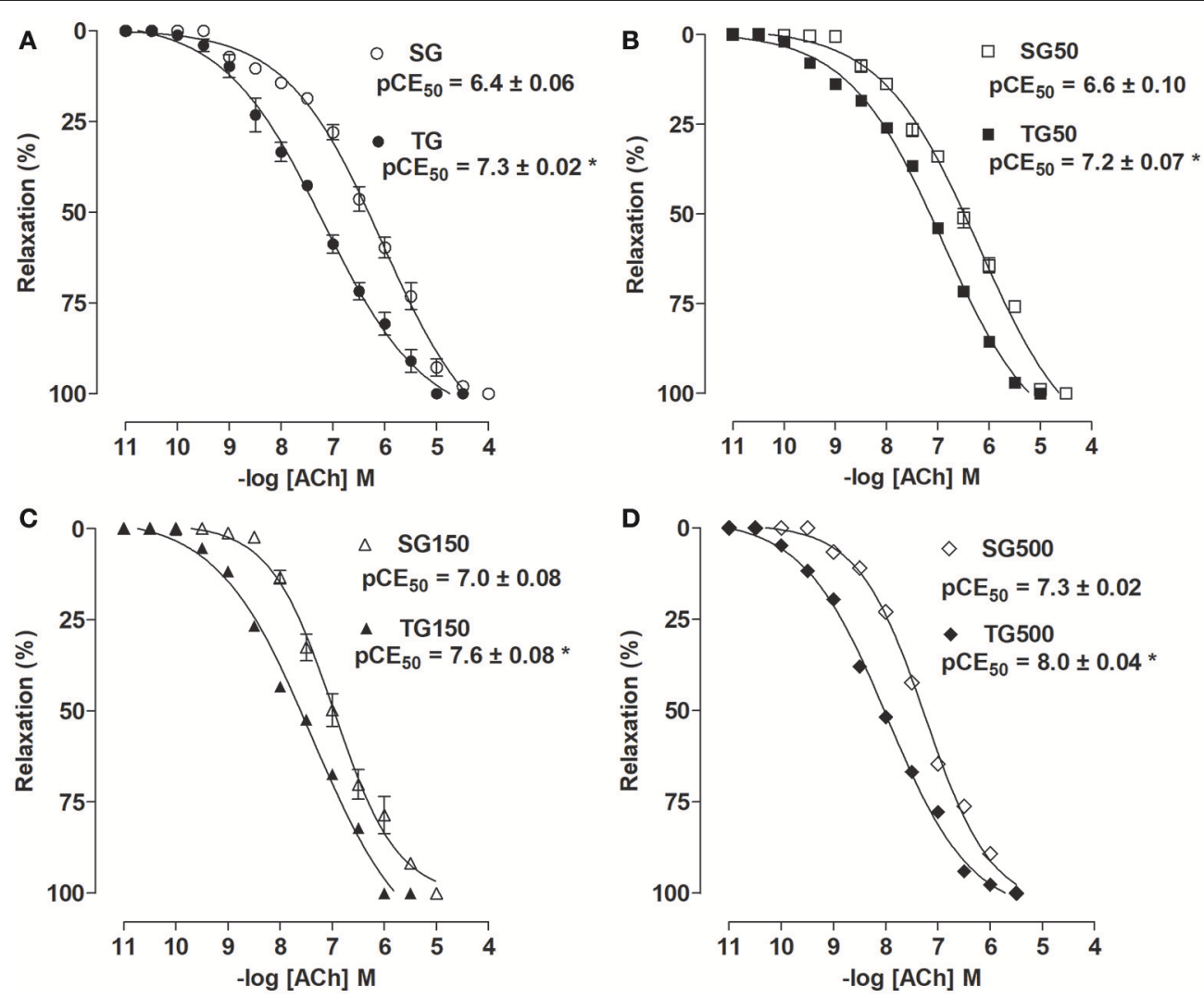

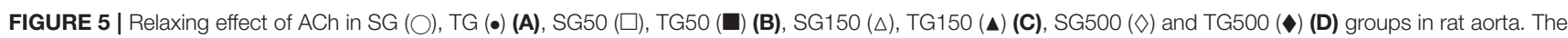
symbols and vertical bars represent the mean and SEM, respectively $(n=5)$. Student's $t$ test, ${ }^{*} p<0.05$ (SG vs. TG, SG50 vs. TG50, SG150 vs. TG150, SG500 vs. TG500).

Strength training potentiated the increase in nitrite production with supplementation of $S$. platensis at all doses tested. The concentration of nitrite on plasma increased from $59.0 \pm 8.0$ (SG50) to $75.0 \pm 13.0 \mu \mathrm{M}$ (TG50), $70.0 \pm 7.0$ (SG150) to 89.0 $\pm 7.0 \mu \mathrm{M}$ (TG150) and $88.0 \pm 7.0$ (SG500) to $112.0 \pm 3.0 \mu \mathrm{M}$ (TG500) (Figure 7A).

In the aorta, it was shown that in all groups subjected to strength training, the production of nitrite was higher than in sedentary groups. The nitrite concentration in rats subjected to strength training alone and sedentary rats was $40.0 \pm 5.0$ and 28.0 $\pm 6.0 \mu \mathrm{M}$, respectively. Strength training potentiated the increase in nitrite levels with supplementation of $S$. platensis with all doses tested. Aortic nitrite concentration values increased from $31.0 \pm$ 10.0 (SG50) to $47.0 \pm 7.0 \mu \mathrm{M}$ (TG50), $43.0 \pm 5.0$ (SG150) to 57.0 $\pm 6.0 \mu \mathrm{M}$ (TG150), and $71.0 \pm 7.0$ (SG500) to $86.0 \pm 5.0 \mu \mathrm{M}$ (TG500) (Figure 7B).

\section{Effect of Strength Training and Supplementation With S. platensis on the Production of Malondialdehyde}

The MDA plasmatic concentration in all groups subjected to strength training was lower than in sedentary groups. The MDA values in rats subjected to strength training alone and sedentary rats were $7.1 \pm 1.0$ and $8.3 \pm 1.1 \mathrm{nmol} / \mathrm{L}$, respectively.
Strength training potentiated the reduction in MDA levels with supplementation of $S$. platensis at all doses tested. MDA values decreased from $8.2 \pm 2.0$ (SG50) to $6.9 \pm 2.0 \mathrm{nmol} / \mathrm{L}$ (TG50), $6.8 \pm 0.7$ (SG150) to $5.6 \pm 0.4 \mathrm{nmol} / \mathrm{L}(\mathrm{TG} 150)$ and $5.0 \pm 0.1$ (SG500) to $3.9 \pm 0.4 \mathrm{nmol} / \mathrm{L}$ (TG500) (Figure 8A).

Comparing the sedentary and exercised groups, strength training potentiated the reduction in MDA production in aorta with supplementation of $S$. platensis at all doses tested. MDA decreased from $26.0 \pm 6.0$ (SG) to $16.0 \pm 3.0 \mu \mathrm{M} / \mathrm{g}$ (TG), 24.0 \pm 2.0 (SG50) to $15.0 \pm 2.0 \mu \mathrm{M} / \mathrm{g}$ (TG50), $18.0 \pm 2.0$ (SG150) to $10.0 \pm 21.0 \mu \mathrm{M} / \mathrm{g}$ (TG150) and $10.0 \pm 3.0$ (SG500) to $5.0 \pm 3.0$ $\mu \mathrm{M} / \mathrm{g}$ (TG500) (Figure 8B).

Similarly, in the heart, it was shown that training potentiated the decrease in MDA when TG was compared to SG $(16.0 \pm 6.0$ vs. $29.0 \pm 4.0 \mu \mathrm{M} / \mathrm{g})$, TG50 was compared to SG50 (15.0 \pm 2.0 vs. $31.0 \pm 6.0 \mu \mathrm{M} / \mathrm{g})$, TG150 was compared to SG150 (12.0 \pm 3.0 vs. $24.0 \pm 3.0 \mu \mathrm{M} / \mathrm{g})$ and TG500 was compared to SG500 (5.0 \pm 3.0 vs. $15.0 \pm 3.0 \mu \mathrm{M} / \mathrm{g}$ ) (Figure $8 \mathrm{C}$ ).

\section{Effect of Strength Training and Supplementation With S. platensis on Antioxidant Activity}

In all groups subjected to strength training, the plasma antioxidant activity was higher than in sedentary groups. 

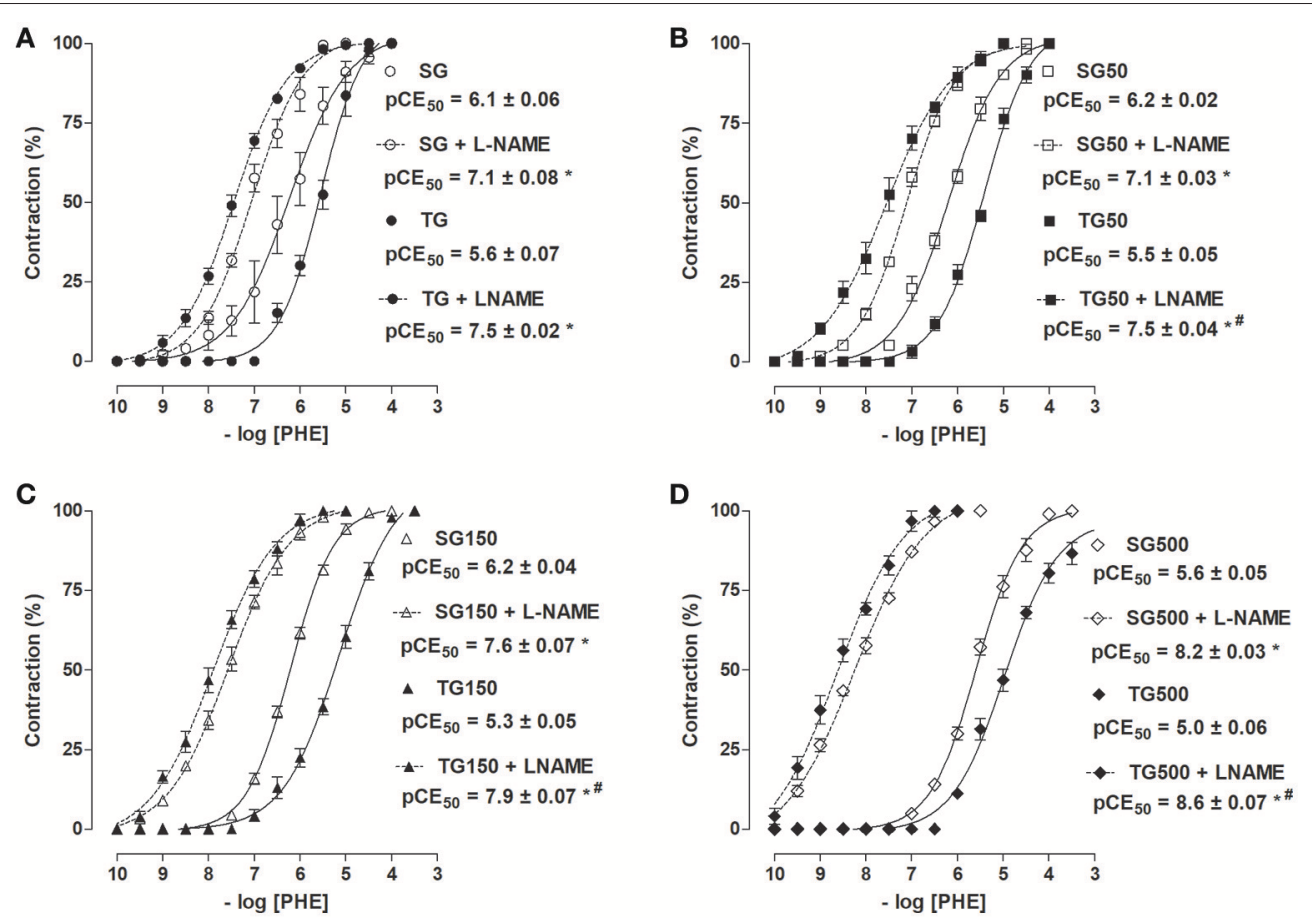

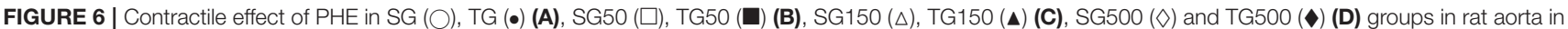
the absence and presence of L-NAME. The symbols and vertical bars represent the mean and SEM, respectively $(n=5)$. Two-way ANOVA followed by Bonferroni's post-test, ${ }^{*} p<0.05$ (SG vs. SG + L-NAME, TG vs. TG + L-NAME, SG50 vs. SG50 + L-NAME, TG50 vs. TG50 + L-NAME, SG150 vs. SG150 + L-NAME, TG150 vs. TG150 + L-NAME, SG500vs. SG500 + L-NAME and TG500 vs. TG500 + L-NAME) and \#p 0.05 (TG + L-NAME vs. SG + L-NAME, TG50 + L-NAME vs. SG50 + L-NAME, TG50 + L-NAME vs. SG50 + L-NAME and TG500 + L-NAME vs. SG500 + L-NAME).

The percentage values in rats subjected to strength training alone and sedentary rats were $65.0 \pm 2.0$ and $50.0 \pm 5.0 \%$, respectively. Strength training enhanced the percentages of antioxidant activity with the supplementation of $S$. platensis at all doses tested. Values increased from $54.0 \pm 4.0$ (SG50) to $67.0 \pm 2.0 \%$ (GT50), $62.0 \pm 3.0$ (SG150) to $82.0 \pm 2.0 \%$ (GT150), and $74.0 \pm 2.0$ (SG500) to $93.0 \pm 2.0 \%$ (GT500) (Figure 8D).

In aorta, comparing the sedentary and exercised groups, strength training enhanced antioxidant activity with the supplementation of $S$. platensis at all doses tested. Values increased from $12.0 \pm 4.0$ (SG) to $25.0 \pm 7.0 \%$ (GT), $14.0 \pm$ 2.0 (SG50) to $25.0 \pm 5.0 \%$ (GT50), $17.0 \pm 2.0$ (SG150) to $35.0 \pm$ $6.0 \%$ (GT150), and $27.0 \pm 2.0$ (SG500) to $43.0 \pm 3.0 \%$ (GT500)

(Figure 8E).

Similarly, in the heart, it was shown that training potentiated the antioxidant activity when TG was compared to SG $(23.0 \pm$ 3.0 vs. $10.0 \pm 4.0 \%)$, TG50 was compared to SG50 (27.0 \pm 6.0 vs. $11.0 \pm 6.0 \%)$, TG150 was compared to SG150 (32.0 \pm 3.0 vs. $16.0 \pm 3.0 \%)$ and TG500 was compared to SG500 (48.0 \pm 2.0 vs. $30.0 \pm 3.0 \%$ ) (Figure 8 F).

\section{DISCUSSION}

This study showed that chronic supplementation with Spirulina platensis at doses of 150 and $500 \mathrm{mg} / \mathrm{kg}$ decreased contractile reactivity to $\mathrm{PHE}$ and increased relaxing activity to $\mathrm{ACh}$, but when these doses were used in association with strength training, there was potentiation of the reduction in contractile reactivity to $\mathrm{PHE}$ and increase in relaxing activity to ACh. Also, it was shown that the factors that accompanied this improvement in reactivity involve the release of nitric oxide and reduction in oxidative stress and systemic inflammation. Accordingly, these data demonstrated for the first time that the synergistic action between strength training and $S$. platensis results in improving vascular reactivity.

First, to confirm the exercise protocol effectiveness, it was determined that there was a decrease in the time that the animal used to perform the jumps in each series of exercise in the last week of the protocol when compared to the first session, demonstrating the efficacy of the training protocol (Figure 1). Furthermore, there was no significant increase in $\mathrm{LDH}$ or CK activity in any of the trained groups when compared to control group (Figure 2), indicating that despite that strength training was in steps of progressive loads, it did not elicit an exaggerated stress in skeletal muscle, which could lead to the phenomenon called overtraining (Smith, 2004).

The improvement in vascular reactivity, represented by the reduction in the contractile activity (Delbin et al., 2012; Okudan et al., 2012) and increased relaxing activity (Valgas Da Silva et al., 2014) is already well established for the aerobic exercise modality. Concerning the role of strength training in vascular 

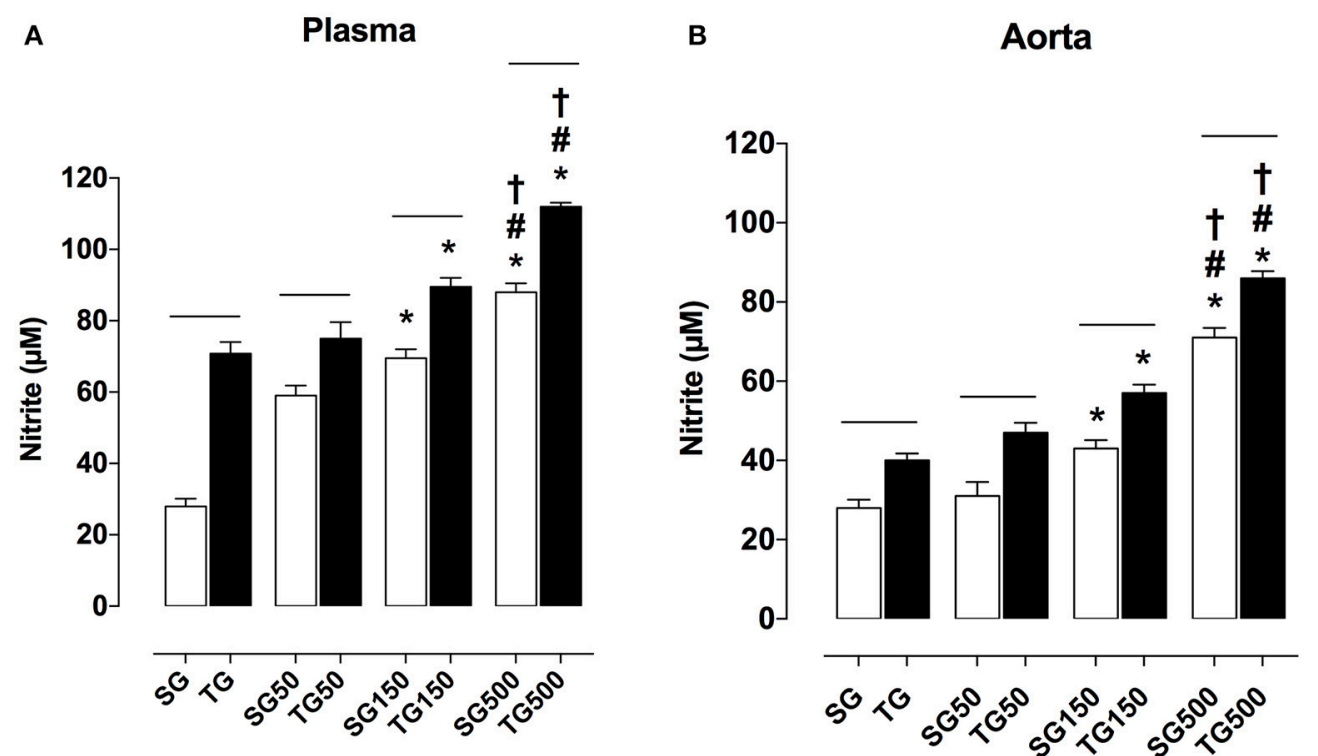

FIGURE 7 | Concentration of nitrite in blood plasma (A) and aorta (B) from SG, TG, SG50, TG50, SG150, TG150, SG500, and TG500 groups, respectively. The columns and vertical bars represent the mean and SEM, respectively $(n=8)$. Two-way ANOVA followed by Bonferroni's post-test, ${ }^{*} p<0.05$ (SG vs. SG150, SG vs. SG500, TG vs. TG150 and TG vs. SG500), \#p < 0.05 (SG50 vs. SG500 and TG50 vs. TG500), ${ }^{\dagger} p<0.05$ (SG150 vs. SG500 and TG150 vs. TG500), - $p<0.05$ (TG vs. SG, TG50 vs. SG50, TG150 vs. SG150 and TG500 vs. SG500).
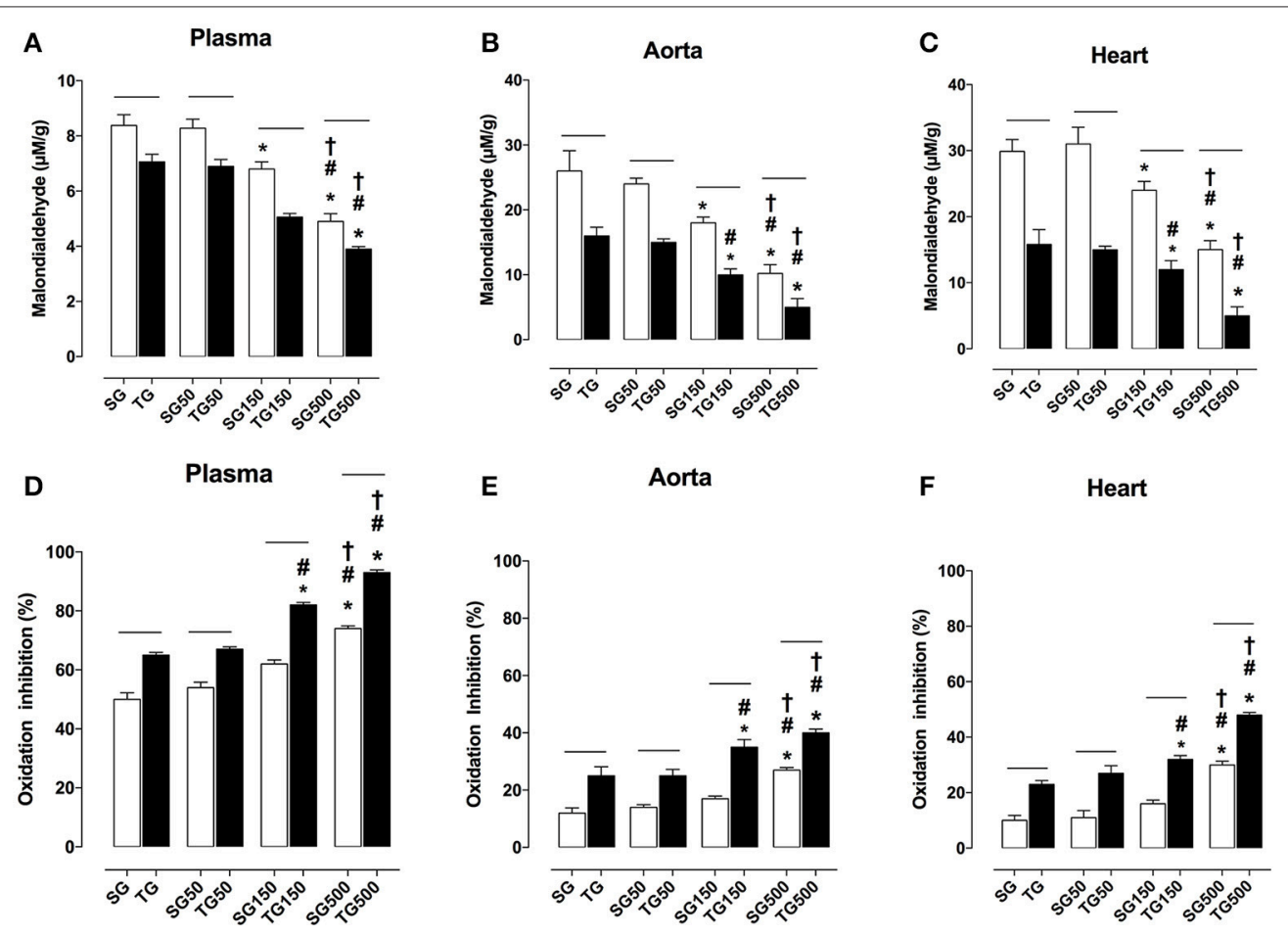

FIGURE 8 | Lipid peroxidation in blood plasma (A), aorta (B), heart (C) and percentage of oxidation inhibition in blood plasma (D), aorta (E), heart (F) from SG, TG, SG50, TG50, SG150, TG150, SG500, and TG500 groups, respectively. The columns and vertical bars represent the mean and SEM, respectively ( $n=8$ ). Two-way ANOVA followed by Bonferroni's post-test, ${ }^{*} p<0.05$ (SG vs. SG150, SG vs. SG500, TG vs. TG150 and TG vs. TG500), \# $p<0.05$ (SG50 vs. SG150, SG50 vs. SG500, TG50 vs. TG150 and TG50 vs. TG500), ${ }^{\dagger} p<0.05$ (SG150 vs. SG500 and TG150 vs. TG500), $-p<0.05$ (TG vs. SG, TG50 vs. SG50, TG150 vs. SG150 and TG500 vs. SG500). 
reactivity, three studies have demonstrated improvement in relaxing activity (Figard et al., 2006; Harris et al., 2010; Araujo et al., 2013) and only in one of them the contractile reactivity with a reduction in this activity was measured (Araujo et al., 2013).

Despite the changes in vascular responsiveness as a result of the resistance exercise investigated, training protocols are quite different and far from what could be extrapolated to humans. Figard et al. (2006) performed an isometric strength training for a period of 14 weeks in rats and evaluated the relaxing activity in aortic rings through cumulative curves to ACh. Harris et al. (2010) subjected aged rats to a strength training that consisted in climbing a ladder with a workload tied to the base of their tail for 6 weeks and the femoral artery relaxing activity was evaluated by concentration-response curves to ACh. More recently, Araujo et al. (2013) subjected hypertensive animals to a four-week training, held three times a week with a continuous load of $50 \%$ of 1 maximum repetition and 3 sets of 10 repetitions prompted by electrical stimulation through electrodes attached to tail, and after this training, the vascular reactivity to PHE was measured in the mesenteric artery. Although they were different methodological models with relaxing activity being significantly improved, the results are still very scarce in the study and none have been done more than one test.

Meanwhile, in this study, as well as simultaneously evaluating the relaxing and contractile activity, the training protocol used was similar to that practiced by humans in real conditions of physical activity, with jumping exercises, simulating the squat exercise (Garber et al., 2011).

This protocol has already been proposed to induce muscle hypertrophy in rats (Marqueti et al., 2006). Thus, these data showed that the improved relaxing effect and reduced contractile response already established in the literature for aerobic training was also observed for the strength training adopted in this study with characteristics closer to that adopted by humans. Thus, our results suggest that a better vasodilation and inhibition of vasoconstriction (Figures 3-5) could explain the reduction in blood pressure that has been observed in humans who undergo strength training programs, as well described by others (Brito et al., 2011, 2014) and in published meta-analyses (Anunciação and Polito, 2011). However, to confirm this assumption, this method should be used again in future studies with hypertensive rats.

Considering that (Huang et al., 2005) demonstrated that oral administration of polysaccharides of $S$. platensis at doses of $12.261,36.783$, and $110.349 \mathrm{mg} / \mathrm{kg}$, during six-week, in diabetic rats improved vascular reactivity. Indeed, the greatest reductions in contractile potency (Figure 3 ) and the largest increases in relaxing potency were identified (Figure 5) in the trained groups supplemented concurrently with doses of 150 and $500 \mathrm{mg} / \mathrm{kg}$ of S. platensis, indicating a synergistic effect between training and nutritional supplementation with $S$. platensis. Additionally, the data obtained in this study demonstrated that supplementation at doses of 150 and $500 \mathrm{mg} / \mathrm{kg}$ was able to improve the reduction in contractile response and increase in relaxation that had been demonstrated with the protocol consisting only of strength training.
The constituents present in S. platensis, such as phycocyanin, can chronically increase the expression of endothelial NOS and consequently promote a greater bioavailability of NO (Ichimura et al., 2013). In previous studies consisted of strength training protocols, two confirmed that the improvement in relaxing effect occurred by mechanisms dependent on endothelium via increased production of $\mathrm{NO}$, a relaxant factor derived from endothelium (Figard et al., 2006) and the increased of Hsp90 expression, a regulator of eNOS activity and binding (Harris et al., 2010). Although Araujo et al. (2013) found for the first time a reduction in contractile reactivity in response to strength training, the mechanism involved was not investigated, but it was noted that the decrease in absence of elevated blood pressure under the conditions of this study, appeared to involve a regulatory vasoconstrictor mechanism.

In this study, it was sought to determine whether the reduction in contractile activity would also be dependent on mechanisms mediated by the endothelium. Accordingly, it was not observed a decrease in the contractile response in rats subjected to the training and supplementation with S. platensis in the absence of the endothelium (Figure 4), demonstrating that the contractile activity inhibition promoted both by strength training and $S$. platensis was dependent on endothelium.

In the presence of L-NAME, a non-selective competitive inhibitor of NOS, it was observed an increase in PHE contractile response elicited by training and supplementation with $S$. platensis (Figure 6). It is established that the practice of exercise training and bioactive compounds present in natural products stimulate the increase in NO bioavailability (Spier et al., 2004; Durrant et al., 2009; Corbi et al., 2016), and consequently, improve endothelium-dependent vasodilation (DeVan et al., 2013; Luttrell et al., 2013). Based on the results obtained by this study and the literature, the participation of the NO pathway on the beneficial effects promoted by exercise training and food supplementation with $S$. platensis can be suggested.

The endothelium role in the reduction of contractile activity was accompanied by an increase in the production of nitrite in plasma and aorta at doses of 150 and $500 \mathrm{mg} / \mathrm{kg}$ of S. platensis and in trained rats. These effects were potentiated when training and food supplementation with $S$. platensis were used concomitantly (Figure 7). Briefly, nitrite concentrations for SG150 and SG500, TG150, and TG500 in plasma and aorta were significantly higher; indicating that food supplementation with the powder of $S$. platensis increased the bioavailability of NO in plasma and tissue, and enhanced the effect of strength training (Figure 7). Similarly, the study pioneered in directly investigating the vasocontractile function improvement in response to strength training and its relationship with the production of NO, which was enhanced by food supplementation with $S$. platensis.

Previously, it was shown that endothelial dysfunction is mainly a result of impaired NO availability leading to increased production of ROS (Tang and Vanhoutte, 2010). Accordingly, the MDA production was determined, a lipid peroxidation marker, as well as the oxidation inhibition percentage, an antioxidant activity marker, in samples of the aorta and cardiac muscle. With regard to lipid peroxidation, it was shown a reduction in MDA potentiated when animals were subjected to training 
and food supplementation with S. platensis at doses of 150 and $500 \mathrm{mg} / \mathrm{kg}$ (Figures $\mathbf{8 A}-\mathbf{C}$ ). In relation to antioxidant activity, it was demonstrated that the oxidation inhibition percentage was increased with training and supplementation with S. platensis (Figures 8D-F). Thus, these results were associated with a decrease in oxidative stress observed in response to strength training and supplementation with $S$. platensis.

The phycocyanin present in S. platensis stands out for its high antioxidant capacity and potent scavenging of free radicals due to its stability (Bhat and Madyastha, 2000) and inhibitory effect on the formation of superoxide radicals by reducing the expression of subunit $\mathrm{p} 22^{\mathrm{phox}}$ of nicotinamide adenine dinucleotide phosphate of oxidase (McCarty, 2007; Kuddus et al., 2013). Moreover, the carotenoids are also essential for the regulation of SOD and catalase (CAT), and blocking free radicals by chelation of metal ions, preventing lipid peroxidation (Cuvelier, 2001). Furthermore, B vitamins and vitamin $\mathrm{E}$ also act as antioxidants via capture of radicals and metal chelating agents (Cuvelier, 2001).

According to this study results, it is worth investigating the potential of $S$. platensis as a nutraceutical and food supplement, to bring an alternative to the region's economy. However, for this to happen, further studies are needed to add to these presented data, for example, in animal models of certain diseases such as hypertension, diabetes and/or obesity.

Pharmacological studies using an experimental model smooth muscle have sought to identify effective therapeutic strategies in the treatment of various diseases such as cardiovascular diseases. Therefore, this study is the first to demonstrate that the use of Spirulina platensis in association with resistance exercise practice is able to improve the smooth muscle contractile response,

\section{REFERENCES}

Altura, B. M., and Altura, B. T. (1970). Differential effects of substrate depletion on drug-induced contractions of rabbit aorta. Am. J. Physiol. 219, 1698-1705. doi: 10.1152/ajplegacy.1970.219.6.1698

Andres-Lacueva, C., Monagas, M., Khan, N., Izquierdo-Pulido, M., Urpi-Sarda, M., Permanyer, J., et al. (2008). Flavanol and flavonol contents of cocoa powder products: influence of the manufacturing process. J. Agric. Food Chem. 56, 3111-3117. doi: 10.1021/jf0728754

Anunciação, P. G., and Polito, M. D. (2011). A review on post-exercise hypotension in hypertensive individuals. Arq. Bras. Cardiol. 96, e100-e109. doi: 10.1590/S0066-782X2011005000025

Araujo, A. J. S., Santos, A. C. V., Souza, K. S., Aires, M. B., Santana-Filho, V. J., Fioretto, E. T., et al. (2013). Resistance training controls arterial blood pressure in rats with L-NAME-induced hypertension. Arq. Bras. Cardiol. 100, 339-346. doi: 10.5935/abc.20130051

Barrajon-Catalan, M. E., Herranz-Lopez, J. J., Segura-Carretero, A., AlonsoVillaverde, C., Menendez, J. A., and Micol, V. (2014). Molecular promiscuity of plantpolyphenols in the management of age-related diseases: far beyond theirantioxidant properties. Adv. Exp. Med. Biol. 824, 141-159. doi: 10.1007/978-3-319-07320-0_11

Beck, D. T., Martin, J. S., Casey, D. P., and Braith, R. W. (2014). Exercise training improves endothelial function in resistance arteries of young prehypertensives. J. Hum. Hypertens. 28, 303-309. doi: 10.1038/jhh. 2013.109 to promote increased antioxidant activity and decreased prooxidant activity, indicating that the association between these therapies can be a non-pharmacological instrument for the treatment and prevention of diseases arising from the smooth muscle.

Therefore, it was concluded that strength training in association with food supplementation of S. platensis improves muscle performance and protects against muscle damage, oxidative stress, and inflammation. In addition, it decreased the contractile reactivity induced by $\mathrm{PHE}$ and increased the relaxing response to $\mathrm{ACh}$ in the aorta with endothelium. These responses were mediated by factors dependent on vascular endothelium, such as increased NO bioavailability in plasma and aorta, reduced lipid peroxidation and increased antioxidant activity in plasma, aorta, and heart.

\section{AUTHOR CONTRIBUTIONS}

$\mathrm{AB}, \mathrm{AS}$ and $\mathrm{BdS}$ developed the hypothesis and experimental design. $\mathrm{AB}, \mathrm{IdS}$, and $\mathrm{LA}$ analyzed the data and wrote the manuscript. AB, IdS, and PF performed the experimental work. RT, AdS, GF, RP, MM, and LA contributed to the in vivo work. RS and MS contributed to the in vitro work.

\section{ACKNOWLEDGMENTS}

We thank Coordenação de Aperfeiçoamento de Pessoal de Nível Superior (CAPES), Conselho Nacional de Desenvolvimento Científico e Tecnológico $(\mathrm{CNPq})$ and Fundação de Apoio à Pesquisa do Estado da Paraíba (FAPESQ-PB) for their financial support and Federal University of Paraíba for logistical support.
Bhat, V. B., and Madyastha, K. M. (2000). C-phycocyanin: a potent peroxyl radical scavenger in vivo and in vitro. Biochem. Biophys. Res. Commun. 275, 20-25. doi: $10.1006 /$ bbrc. 2000.3270

Blanco-Rivero, J., Roque, F. R., Sastre, E., Caracuel, L., Couto, G. K., Avendaño, M. S., et al. (2013). Aerobic exercise training increases neuronal nitric oxide release and bioavailability and decreases noradrenaline release in mesenteric artery from spontaneously hypertensive rats. J. Hypertens. 31, 916-926. doi: 10.1097/HJH.0b013e32835f749c

Brand-Williams, W., Cuvelier, M. E., and Berset, C. (1995). Use of a free radical method to evaluate antioxidant activity. J. Food Sci. Technol. 28, 25-30. doi: 10.1016/S0023-6438(95)80008-5

Brito, A. F., Alves, N. F. B., Souza, A. A., Goncalves, M. C. R., and Silva, A. S. (2011). Active intervals between sets of resistance exercises potentiate the magnitude of postexercise hypotension in elderly hypertensive women. J. Strength Cond. Res. 25, 3129-3136. doi: 10.1519/JSC.0b013e318212dd25

Brito, A. F., Oliveira, C. V. C., Santos, M. S. B., and Santos, A. C. (2014). Highintensity exercise promotes postexercise hypotension greater than moderate intensity in elderly hypertensive individuals. Clin. Physiol. Funct. Imag. 34, 126-132. doi: 10.1111/cpf.12074

Choi, Y., Akazawa, N., Miyaki, A., Ra, S. G., Shiraki, H., Ajisaka, R., et al. (2016). Acute effect of high-intensity eccentric exercise on vascular endothelial function in young men. J. Strength Cond. Res. 30, 2279-2285. doi: 10.1519/JSC.0000000000000536

Conti, V., Corbi, G., Russomanno, G., Simeon, V., Ferrara, N., Filippelli, W., et al. (2012). Oxidative stress effects on endothelial cells treated 
with different athletes' sera. Med. Sci. Sports Exerc. 44, 39-49. doi: 10.1249/MSS.0b013e318227f69c

Corbi, G., Conti, V., Davinelli, S., Scapagnini, G., Filippelli, A., and Ferrara, N. (2016). Dietary phytochemicals in neuroimmunoaging: a new therapeutic possibility for humans? Front. Pharmacol. 7:364. doi: 10.3389/fphar.2016. 00364

Cuvelier, M. E. (2001). "Antioxidants," in Functional Foods: An Introductory Course, ed R. Morais (Porto: Universidade Católica Portuguesa-Escola Superior de Biotecnologia), 95-105.

Davinelli, S., Corbi, G., Righetti, S., Sears, B., Olarte, H. H., Grassi, D., et al. (2018). Cardioprotection by cocoa polyphenols and $\omega$-3 fatty acids: a diseaseprevention perspective on aging-associated cardiovascular risk. J. Med. Food 21, 1060-1069. doi: 10.1089/jmf.2018.0002

Davinelli, S., Maes, M., Corbi, G., Zarrelli, A., Willcox, D. C., and Scapagnini, G. (2016). Dietary phytochemicals and neuro-inflammaging: from mechanistic insights to translational challenges. Immun. Ageing 13:16. doi: 10.1186/s12979-016-0070-3

Davinelli, S., Scapagnini, G., Marzatico, F., Nobile, V., Ferrara, N., and Corbi, G. (2017). Influence of equol and resveratrol supplementation on health-related quality of life in menopausal women: a randomized, placebo-controlled study. Maturitas 96, 77-83. doi: 10.1016/j.maturitas.2016.11.016

Delbin, M. A., Davel, A. P., Couto, G. K., de Araújo, G. G., Rossoni, L. V., Antunes, E., et al. (2012). Interaction between advanced glycation end products formation and vascular responses in femoral and coronary arteries from exercised diabetic rats. PLoS ONE 7:e53318. doi: 10.1371/journal.pone.0053318

DeVan, A. E., Eskurza, I., Pierce, G. L., Walker, A. E., Jablonski, K. L., Kaplon, R. E., et al. (2013). Regular aerobic exercise protects against impaired fasting plasma glucose-associated vascular endothelial dysfunction with aging. Clin. Sci. 124, 325-331. doi: $10.1042 / C S 20120291$

Durrant, J. R., Seals, D. R., Connell, M. L., Russell, M. J., Lawson, B. R., Folian, B. J., et al. (2009). Voluntary wheel running restores endothelial function in conduit arteries of old mice: direct evidence for reduced oxidative stress, increased superoxide dismutase activity and down-regulation of NADPH oxidase. J. Physiol. 587, 3271-3285. doi: 10.1113/jphysiol.2009.169771

Ferrara, N., Rinaldi, B., Corbi, G., Conti, V., Stiuso, P., Boccuti, S., et al. (2008). Exercise training promotes SIRT1 activity in aged rats. Rejuvenation Res. 11, 139-150. doi: 10.1089/rej.2007.0576

Figard, H., Gaume, V., Mougin, F., Demougeot, C., and Berthelot, A. (2006). Beneficial effects of isometric strength training on endothelial dysfunction in rats. Appl. Physiol. Nutr. Metab. 31, 621-630. doi: 10.1139/h06-070

Furchgott, R., and Zawadki, J. (1980). The obligatory role of endothelium cell in the relaxation of arterial smooth muscle by acetylcholine. Nature 288, 373-376. doi: $10.1038 / 288373 \mathrm{a} 0$

Garber, C. E., Blissmer, B., Deschenes, M. R., Franklin, B. A., Lamonte, M. J., Lee, I. M., et al. (2011). Quantity and quality of exercise for developing and maintaining cardiorespiratory, musculoskeletal, and neuromotor fitness in apparently healthy adults: guidance for prescribing exercise. Med. Sci. Sports Exerc. 43, 1334-1359. doi: 10.1249/MSS.0b013e318213fefb

Green, L. C., Tannenbaum, S. R., and Goldman, P. (1981). Nitrate synthesis in the germfree and conventional rat. Science 212, 56-58. doi: $10.1126 /$ science. 6451927

Harris, M. B., Slack, K. N., Prestosa, D. T., and Hryvniak, D. J. (2010). Resistance training improves femoral artery endothelial dysfunction in aged rats. Eur. J. Appl. Physiol. 108, 533-540. doi: 10.1007/s00421-009-1250-z

Heylen, E., Guerrero, F., Mansourati, J., Theron, M., Thioub, S., and Saïag, B. (2008). Effect of training frequency on endothelium-dependent vasorelaxation in rats. Eur. J. Cardiovasc. Prev. Rehabil. 15, 52-58. doi: 10.1097/HJR.0b013e3282f17baa

Huang, Z. X., Mei, X. T., Xu, D. H., Xu, S. B., and Lv, J. Y. (2005). Protective effects of polysacchride of Spirulina platensis and Sargassum thunbeergii on vascular of alloxan induced diabetic rats. Zhongguo Zhong Yao Za Zhi 30, 211-215.

Ichimura, M., Kato, S., Tsuneyama, K., Matsutake, S., Kamogawa, M., Hirao, E., et al. (2013). Phycocyanin prevents hypertension and low serum adiponectin level in a rat model of metabolic syndrome. Nutr. Res. 33, 397-405. doi: 10.1016/j.nutres.2013.03.006

Juárez-Oropeza, M. A., Mascher, D., Torres-Durán, P. V., Farias, J. M., and Paredes-Carbajal, M. C. (2009). Effects of dietary Spirulina on vascular reactivity. J. Med. Food 12, 15-20. doi: 10.1089/jmf.2007.0713
Kuddus, M., Singh, P., Thomas, G., and Al-Hazimi, A. (2013). Recent developments in production and biotechnological applications of Cphycocyanin. Biomed Res. Int. 2013:742859. doi: 10.1155/2013/742859

Lau, F. C., Shukitt-Hale, B., and Joseph, J. A. (2007). Nutritional intervention in brain aging: reducing the effects of inflammation and oxidative stress. Subcell. Biochem. 42, 299-318. doi: 10.1007/1-4020-5688-5_14

Luttrell, M. J., Seawright, J. W., Wilson, E., and Woodman, C. R. (2013). Effect of age and exercise training on protein:protein interactions among eNOS and its regulatory proteins in rat aortas. Eur. J. Appl. Physiol. 113, 2761-2768. doi: 10.1007/s00421-013-2715-7

Manach, C., Scalbert, A., Morand, C., Rémésy, C., and Jime’nez, L. (2004). Polyphenols: food sources and bioavailability. Am. J. Clin. Nutr. 79, 727-747. doi: 10.1093/ajen/79.5.727

Marqueti, R. C., PArizotto, N. A., Chriguer, R. S., Perez, S. E., and Selistrede-Araujo, H. S. (2006). Androgenic-anabolic steroids associated with mechanical loading inhibit matrix metallopeptidase activity and affect the remodeling of the achilles tendon in rats. Am. J. Sports Med. 34, 1274-1280. doi: $10.1177 / 0363546506286867$

McCarty, M. F. (2007). Clinical potential of Spirulina as a source of phycocyanobilin. J. Med. Food 10, 566-570. doi: 10.1089/jmf.2007.621

Neubig, R. R., Spedding, M., Kenakin, T., and Christopoulos, A. (2003). International Union of Pharmacology Committee on Receptor Nomenclature and Drug Classification. XXXVIII. Update on terms and symbols in quantitative pharmacology. Pharmacol. Rev. 55, 597-606. doi: 10.1124/pr.55.4.4

Ohkawa, H., Ohishi, N., and Yagi, K. (1979). Assay for lipid peroxides in animal tissues by thiobarbituric acid reaction. Anal. Biochem. 95, 351-358. doi: 10.1016/0003-2697(79)90738-3

Okafor, O., Erukainure, O., Ajiboye, J., Adejobi, R., Owolabi, F., and Kosoko, S. (2011). Modulatory effect of pineapple peel extract on lipid peroxidation, catalase activity and hepatic biomarker levels in blood plasma of alcoholinduced oxidative stressed rats. Asian Pac. J. Trop. Biomed. 1, 12-14. doi: 10.1016/S2221-1691(11)60060-9

Okudan, N., Nurullahoglu-Atalik, K. E., Revan, S., and Belviranli, M. (2012). Effects of treatment with coenzyme Q10 on exercised rat aorta. Acta Physiol. Hung. 99, 40-50. doi: 10.1556/APhysiol.99.2012.1.5

Roque, F. R., Briones, A. M., García-Redondo, A. B., Galán, M., MartínezRevelles, S., Avendaño, M. S., et al. (2013). Aerobic exercise reduces oxidative stress and improves vascular changes of small mesenteric and coronary arteries in hypertension. Br. J. Pharmacol. 168, 686-703. doi: $10.1111 / j .1476-5381.2012 .02224 . x$

Scapagnini, G., Vasto, S., Abraham, N. G., Caruso, C., Zella, D., and Fabio, G. (2011). Modulation of Nrf2/ARE pathway by food polyphenols: a nutritional neuroprotective strategy for cognitive and neurodegenerative disorders. Mol. Neurobiol. 44, 192-201. doi: 10.1007/s12035-011-8181-5

Scheffer, D. L., Silva, L. A., Tromm, C. B., da Rosa, G. L., Silveira, P. C., de Souza, C. T., et al. (2012). Impact of different resistance training protocols on muscular oxidative stress parameters. Appl. Physiol. Nutr. Metab. 37, 12391246. doi: 10.1139/h2012-115

Schoenfeld, B. J. (2010). The mechanisms of muscle hypertrophy and their application to resistance training. J. Strength Cond. Res. 24, 2857-2872. doi: 10.1519/JSC.0b013e3181e840f3

Sherwin, C. M., Christiansen, S. B., Duncan, I. J. H., Erhard, H. W., Lay Jr, D. C., Mench, J. A., et al. (2005). Guidelines for the ethical use of animals in applied animal behaviour research. J. Appl. Toxicol. 25, 496-513.

Siekmann, L., Bonora, R., Burtis, C. A., Ceriotti, F., Clerc-Renaud, P., Férard, G., et al. (2002). Certification of four reference materials for the determination of enzymatic activity of gamma-glutamyltransferase, lactate dehydrogenase, alanine aminotransferase and creatine kinase accord. Clin. Chem. Lab. Med. 40, 739-745. doi: 10.1515/CCLM.2002.127

Silva, D. M., Gomes-Filho, A., Olivon, V. C., Santos, T. M., Becker, L. K., Santos, R. A., et al. (2011). Swimming training improves the vasodilator effect of angiotensin-(1-7) in the aorta of spontaneously hypertensive rat. J Appl Physiol. 111, 1272-1277. doi: 10.1152/japplphysiol.00034.2011

Smith, L. L. (2004). Tissue trauma: the underlying cause of overtraining syndrome? J. Strength Cond. Res. 18, 185-193. doi: 10.1519/00124278-20040200000028

Spier, S. A., Delp, M. D., Meininger, C. J., Donato, A. J., Ramsey, M. W., and Muller-Delp, J. M. (2004). Effects of ageing and exercise training on 
endothelium-dependent vasodilatation and structure of rat skeletal muscle arterioles. J. Physiol. 556, 947-958. doi: 10.1113/jphysiol.2003.060301

Stefani, G. P., Nunes, R. B., Dornelles, A. Z., Alves, J. P., Piva, M. O., Domenico, M. D., et al. (2014). Effects of creatine supplementation associated with resistance training on oxidative stress in different tissues of rats. J. Int. Soc. Sports Nutr. 11:11. doi: 10.1186/1550-2783-11-11

Tang, E. H., and Vanhoutte, P. M. (2010). Endothelial dysfunction: a strategic target in the treatment of hypertension? Pflugers Arch. 459, 995-1004. doi: 10.1007/s00424-010-0786-4

Trinity, J. D., Wray, D. W., Witman, M. A., Layec, G., Barrett-O'Keefe, Z., Ives, S. J., et al. (2013). Contribution of nitric oxide to brachial artery vasodilation during progressive handgrip exercise in the elderly. Am. J. Physiol. Regul. Integr. Comp. Physiol. 305, R893-R899. doi: 10.1152/ajpregu.00311.2013

Valgas Da Silva, C. P., Rojas-Moscoso, J. A., Antunes, E., Zanesco, A., and Priviero, F. B. (2014). L-Carnitine supplementation impairs endothelium-dependent relaxation in mesenteric arteries from rats. Arch. Physiol. Biochem. 120, 112118. doi: $10.3109 / 13813455.2014 .928731$

Virdis, A., Neves, M. F., Duranti, E., Bernini, G., and Taddei, S. (2013). Microvascular endothelial dysfunction in obesity and hypertension.
Curr. Pharm. Des. 19, 2382-2389. doi: 10.2174/13816128113191 30006

Wu, H. L., Chen, T. F., Yin, X., and Zheng, W. J. (2012). Spectrometric characteristics and underlying mechanisms of protective effects of selenium on Spirulina platensis against oxidative stress. Guang Pu Xue Yu Guang Pu Fen Xi 32, 749-754. doi: 10.3964/j.issn.1000-0593(2012)03-0749-06

Conflict of Interest Statement: The authors declare that the research was conducted in the absence of any commercial or financial relationships that could be construed as a potential conflict of interest.

Copyright (๐ 2018 Brito, Silva, de Souza, Ferreira, de Souza, Araujo, Félix, Sampaio, Silva, Tavares, Pereira, Miranda Neto and da Silva. This is an open-access article distributed under the terms of the Creative Commons Attribution License (CC BY). The use, distribution or reproduction in other forums is permitted, provided the original author(s) and the copyright owner(s) are credited and that the original publication in this journal is cited, in accordance with accepted academic practice. No use, distribution or reproduction is permitted which does not comply with these terms. 